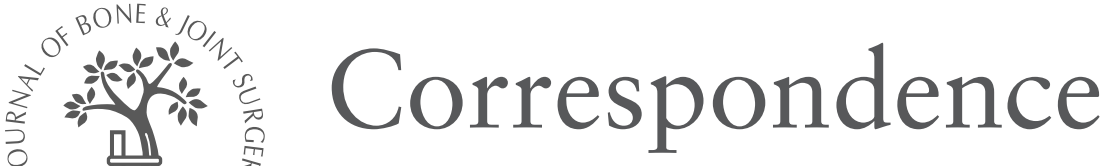

We welcome letters to the Editor concerning articles which have recently been published. Such letters will be subject to the usual stages of selection and editing; where appropriate the authors of the original article will be offered the opportunity to reply.

Letters should normally be under $\mathbf{3 0 0}$ words in length, doublespaced throughout, signed by all authors and fully referenced. The edited version will be returned for approval before publication.

(C)2004 British Editorial Society of Bone and Joint Surgery doi:10.1302/0301-620X.86B5.15574 \$2.00

J Bone Joint Surg [Br] 2004;86-B:777-8.

\section{Hip fracture in the immobile patient}

Sir,

I read with interest the article in the September 2003 issue by Hay and Parker ${ }^{1}$ entitled 'Hip fracture in the immobile patient'.

The article indicated that there is little support for immobility as an indication for conservative treatment of hip fractures. I agree that their prospective review produced informative and interesting data. I notice that they operated on all immobile patients that they considered fit for surgery so that there was no control group with which to compare outcome. They described 38 post-operative complications and 19 patients died whilst still in hospital. They conclude that immobility in patients with hip fractures is common and is not a valid reason for withholding surgical treatment. This statement may be correct, but I do not believe that this conclusion can be taken from the presented data. In mobile patients it is well known that the benefits of early mobilisation is a valid reason for exposing patients with hip fractures to the risks of surgery. In immobile patients, justification for surgery could be reduction of morbidity and mortality but I do not believe that this has been demonstrated by the authors after surgical fixation.

\section{S. EHRENDORFER}

Wishaw General Hospital

Wishaw, Scotland.

1. Hay D, Parker MJ. Hip fracture in the immobile patient. J Bone Joint Surg $[\mathrm{Br}]$ 2003;85-B:1037-9

\section{Author's reply:}

Sir,

We thank Mr Ehrendorfer for his letter and interest in our article.

We have to agree with the comments expressed in that we have no control group of patients treated conservatively. Neither were we able to find any such reports in the literature for this group of patients. The conclusions that immobility should not be used to withhold surgery, is our opinion based on our experience and audit of results. Our reported results should be used to compare against those who favour a more conservative approach and we hope such series will be reported to enable the clinician to have a more informed method of determining treatment.

\author{
M. PARKER, MD, FRCS \\ D. HAY, FRCS \\ Peterborough District Hospital \\ Peterborough, UK.
}

\section{Arthroscopic treatment of osteochondral lesions of the talus}

Sir,

Our Journal Club read with interest the article by Robinson et al ${ }^{1}$ in the September 2003 issue entitled 'Arthroscopic treatment of osteochondral lesions of the talus'. We would like to raise the following points.

The basis on which osteochondral lesions of the talus were classified as traumatic or atraumatic was not stated. For each of these categories different starting points were used to determine the time to presentation, namely the time from trauma for traumatic and duration of symptoms for atraumatic. We feel these facts would affect the outcome of assessment of the time to operation and the outcome of surgery.

The outcome groups (good, fair and poor) included patients with differing sides and stages of lesion and differing treatments. Also, of the 65 patients studied, 54 had 57 other pathologies in the affected foot. Of these, 12 had other procedures performed at the time of osteochondral surgery as well as an unamed number having operative stabilisation. Given the number of confounding variables we believe the outcome results should be interpreted with caution.

\section{J. R. GIBBS, SpR}

D. RICKETTS

Princess Royal Hospital

West Sussex, UK.

1. Robinson DE, Harries IG, Kelly AJ. Arthroscopic treatment of osteochondral lesions of the talus. J Bone Joint Surg [Br] 2003;85-B:989-93.

\section{Author's reply}

Sir,

We thank Messrs Gibbs and Ricketts for their comments relating to our article and the opportunity to clarify certain matters. For those patients classified as having a traumatic origin, their symptoms began following a significant event that could be directly related to the onset of symptoms whereas in atraumatic cases there was no such event. Patients usually complained that the ankle never felt right following the injury and that those same symptoms progressed, therefore, we felt confident that the osteochondral lesion occurred at this time. Thus, the time to presentation of the traumatic group corresponded with the time of injury whereas for 
atraumatic lesions the only measure available was duration of symptoms and we do not feel that this biases our results. Our findings that lateral lesions are traumatic in origin and medial lesions may be atraumatic is well described in the literature. ${ }^{1}$

We have found that osteochondral lesions rarely occur entirely in isolation but fortunately the associated pathology can often be effectively treated concomitantly at arthroscopy and we found no association between additional pathology and outcome. One patient underwent a lateral ligament reconstruction with a modified Brostrum technique and of the peroneal retinaculum re-inforcement for an MRI grade 4 lateral lesion and achieved a good outcome while another patient awaited lateral ligament reconstruction due to symptomatic instability that was not addressed at the initial surgery for an MRI grade 5 medial lesions and had a poor outcome.

D. E. ROBINSON, FRCS (TR and Orth)

I. G. WINSON, FRCS

W. J. HARRIES, FRCS ( $\mathrm{Tr}$ and Orth)

A. J. KELLY, FRCS, (Tr and Orth)

Avon Orthopaedic Centre

Southmead Hospital, Bristol, UK.

1. Tol JL, Struijis PA, Bossuyt PM, Verhagen RA, van Dijk CN. Treatment strategies in osteochondral defects of the talar dome: a systematic review. Foot Ankle Int 2000;21:119-26.

\section{Outcome after reconstruction of the anterior cruciate ligament in athletic patients}

Sir,

We read with interest the article in the May 2003 issue by Meighan et $\mathrm{al}^{1}$ entitled 'Outcome after reconstruction of the anterior cruciate ligament in athletic patients'. We appreciate the effective study design and the simple and easy exposition. However, there was no mention of sample size or the statistical power.

It is disappointing that a valid paper is invalidated by the absence of this fundamental information. It is well known ${ }^{2,3}$ that sample size is important to establish the number of people for inclusion in a study in order to provide valid results. The statistical power gives information about the validity of significant results. If the sample is small, the results can be non-significant for this reason.
R. PADUA, MD
R. BONDI
E. CECCARELLI
San Giacom Hospital
Rome, Italy.

1. Meighan AAS, Keating JF, Will E. Outcome after reconstruction of the anterior cruciate ligament in athletic patients. J Bone Joint Surg [Br] 2003;85-B:521-4.

2. Freedman KB, Back S, Bernstein J. Sample size and statistical power of randomised, controlled trials in orthopaedics. J Bone Joint Surg [Br] 2001;83-B:397-402.

3. Pijnenburg ACM, Bogaard K, Krips R, et al. Operative and functional treatment of rupture of the lateral ligament of the ankle. J Bone Joint Surg [Br] 2003;85-B:525-30.

\section{Author's reply:}

Sir,

I accept the criticism made by Dr Padua and his colleagues regarding our article. The sample size was small both in the early and late groups. The difficulties of recruiting patients to this type of surgery were referred to in our discussion. Although a larger sample size in both groups would have been desirable, we were unable to demonstrate any significant advantage for an immediate anterior cruciate ligament (ACL) reconstruction. In fact, the significant differences observed were in favour of delaying the procedure.

We consider that our study does contribute to the debate on this issue as there is an increasing tendency in some parts of the world to carry out immediate ACL reconstruction, without any proper evidence to show support that this is a more effective method of management.

J. F. KEATING, FRCS Ed (Orth)

Royal Infirmary of Edinburgh

Edinburgh, Scotland. 